\title{
Становление и развитие бодибилдинга в Республике Саха (Якутия)
}

Гренадеров А.А. ${ }^{1}$, Пономарева М.С. ${ }^{*}$, Колодезникова М.Г. ${ }^{2}$

${ }^{1}$ Федерация бодибилдинга Республики Саха (Якутия)

Якутск, Россия

${ }^{2}$ Институт физической культуры и спорта Северо-Восточного федерального университета имени М.К. Аммосова»

Якутск, Россия

ORCID: oooo-ooo1-9132-6046, ponmarsem@mail.ru*

ORCID: oooo-ooo3-0327-1976,mgkolod@inbox.ru

\begin{abstract}
Аннотация: Бодибилдинг зародился в стремлении человечества к физическому и духовному совершенству. Идея гармоничного развития личности легла в основу современногободибилдинга.Бодибилдингмалои зученроссийскимиучеными, отсутствует статистическая информация по данному в иду спорта. В Якутии развитие силовых видов спорта связано с именем известного спортсмена, заслуженного тренера Суровецкого А. Е. Когда культуризм признали как вид спорта, был создан спортивный клуб «Спарта» в г. Якутске (1969 г.). Республиканская общественная организация «Федерация бодибилдинга Республики Саха (Якутия)» была организована в 2016 году. Она объединяет граждан в целях популяризации спорта и здорового образа жизни и строит свою деятельность по развитию бодибилдинга по версии IFBB (Международная федерация бодибилдинга) в Республике Саха (Якутия). Материалљ. Изучение становления и развития бодибилдинга в Якутии. Методъ исследования. Анализ литературных данных, документов, опыта работы педагогов и тренеров, сбор и систематизация спортивных результатов и показателей. Резулътатъ. Изучение текущих и архивнв ых документов планирования и отчетности спортивной работы, руководящих материалов и сводных отчетов, планов подготовки спортивных команд спортивной федерации бодибилдинга Республики Саха (Якутия) позволил проследить становление и развитие блдибилдинга в Республике Саха (Якутия) за 50-летний период, выявить основные проблемы развития данного вида спорта в регионе, среди которых недостаточная финансовая поддержка со стороны государственных структур, слабая материально-техническая база в улусах, острая нехватка профессиональных тренеров. Заключение. Учитывая положительную тенденцию и растущий интерес населения к занятиям физической культурой и спортом, положительную динамику роста спортивных залов, можно констатировать, что популяризация вида спорта «бодибилдинг» наращивается. В организации деятельности РОО Федерации бодибилдинга РС (Я) имеются проблемы, решение которых позволит вывести бодибилдинг на качественно новый уровень, повысить качество выступлений якутских атлетов.
\end{abstract}

Ключевые слова: физическая культура и спорт, спортивная федерация, управление, становление и развитие бодибилдинга, Республика Саха (Якутия).

Для цитирования: Гренадеров А.А., Пономарева М.С.*, Колодезникова М.Г. Становление и развитие бодибилдинга в Республике Саха (Якутия). Педагогико-психологические и медикобиологические проблемы физической культуры и спорта. 2020; 15(4): 50-54. DOI: 10.14526/20704798-2020-15-4-50-54

\section{Bodybuilding formation and development in the Republic of Sakha (Yakutia)}

\author{
Aleksandr A. Grenaderov', Maria S. Ponamareva ${ }^{2 *}$, Margarita G. Kolodeznikova ${ }^{2}$ \\ ${ }^{1}$ Bodybuilding Federation of the Republic of Sakha (Yakutia) \\ Yakutsk, Russia \\ ${ }^{2}$ Institute of Physical Culture and Sport of North-Eastern Federal University named after M. K. Ammosov \\ Yakutsk, Russia \\ ORCID: oooo-ooo1-9132-6046, ponmarsem@mail.ru* \\ ORCID: oooo-ooo3-0327-1976,mgkolod@inbox.ru
}




\begin{abstract}
Bodybuilding originated in the desire of mankind to realize physical and spiritual perfection. The idea of the individual's harmonious development formed the basis of modern bodybuilding. Bodybuilding is not studied enough by Russian scientists, there is no statistical information concerning this kind of sport. In Yakutia strength sports development is connected with the name of a well-known athlete, distinguished coach Surovetskiy A.E. When bodybuilding was acknowledged a kind of sport, a sports club "Sparta" was created in Yakutsk (1969). Republican Social Organization "Body-building Federation of the Republic of Sakha (Yakutia)" was organized in 2016. It unites the citizen for sport and healthy life style popularization and it provides body-building development according to IFBB (International Federation of Bodybuilding) in the Republic of Sakha (Yakutia). Materials. Studying body-building formation and development in Yakutia. Research methods. Information sources, documents, teachers' and coaches' experience analysis, sports results and indices gathering and systematization. Results. Studying current and archive documents of sports work planning, controlling materials and overall reports, plans of training sports teams of sports Body-building Federation of the Republic of Sakha (Yakutia) helped to follow body-building formation and development in the Republic of Sakha (Yakutia) during 50 years, helped to reveal the main problems of this kind of sport development in the regionю Among them there are the following problems: insufficient financial support of government structures, weak material-technical base in settlements (ulus), lack of professional coaches. Conclusion. Taking into consideration positive tendency and the increasing interest of population in physical culture and sport, positive dynamics of sports gyms increase, we come to the conclusion that "body-building" popularization becomes wider. There are some problems in the activity of the Republican Social Organization Body-building Federation of the Republic of Sakha (Yakutia). These problems solution would help to develop body-building and improve the quality of Yakut athletes' performances.

Keywords: physical culture and sport, sports Federation, management, formation and development of bodybuilding, Republic of Sakha (Yakutia).
\end{abstract}

For citation: Aleksandr A. Grenaderov, Maria S. Ponamareva*, Margarita G. Kolodeznikova. Bodybuilding formation and development in the Republic of Sakha (Yakutia). Russian Journal of Physical Education and Sport. 2020; 15(4): 50-54. DOI: 10.14526/2070-4798-2020-15-4-50-54

\section{ВВЕДЕНИЕ}

Бодибилдинг зародился в вечном стремлении человечества к физическому и духовному совершенству. В древних государствах, таких как, например, Спарта, где самым важным считалось вырастить из человекан астоящегов оина, огромноев нимание уделялось его в сестороннему развитию. Именно эта вечная идея гармоничного развития личности и легла в основу современного бодибилдинга. Но профессиональный спорт - это мир рекордов и максимального проявления возможностей человека. Только человек, обладающий огромным стремлением, основательными знаниями по анатомии, физиологии, биохимии, диетологии, биомеханике и истинным желанием, сможет достигнуть высоких результатов в этом спорте $[1,2,3]$.

Бодибилдинг мало изучен российскими учеными, отсутствует статистическая и нформация по данному виду спорта $[4,5,6]$.
Цель исследования - изучить становление и развитие бодибилдинга в Якутии.

\section{МАТЕРИАЛЫ И МЕТОДЫ}

Анализ документов - один из широко применяемых и эффективных методов. Исследование литературных данных дополняется ознакомлением с опытом работы педагогов и тренеров. Ценные сведения получены в ходе изучения текущих и архивных документов планирования и отчетности спортивной работы, руководящих материалов и сводных отчетов, планов подготовки спортивных команд спортивной федерации бодибилдинга Республики Саха (Якутия). Большую роль играли сбор и систематизация спортивных результатов и показателей.

\section{РЕЗУЛЬТАТЫ И ОБСУЖДЕНИЕ}

Развитие силовых в идов спорта в Якутии связано с именем известного спортсмена, заслуженного тренера Суровецкого Аскольда 
Евгеньевича. Его отец в тридцатые годы прошлого века был одним из зачинателей физкультурного движения в Якутии. Но тогда культуризм относился к числу «происков капитализма». Около четырех лет Аскольд Суровецкий с друзьями тренировались в условиях подполья. Когда культуризм все-таки признали как вид спорта, то созданный теперь уже официально атлетический клуб единодушно назвали «Спартой». Это был 1969 год - официальный год создания спортивного клуба «Спарта».

В газете «Социалистическая Якутия» была напечатана первая статья о первом мероприятии в ранге официального спортивного учреждения. Её автором был заслуженный тренер Николай Шамаев - «отец тяжелой атлетики Якутии».

Мероприятие проходило в помещении клуба Якутской телеграфно-телефонной станции, было очень много спортсменов и зрителей. На подмостки импровизированной сцены вышли двенадцать отлично сложенных спортсменов. Так, Юрий Попов довольно легко приседал с весом 175 кг, а в становой тяге достиг 235 кг. Руководитель секции Аскольд Суровецкий при росте 165 см и весе 72 кг приседал с грузом 170 кг, выполнял жим лежа - 120 кг и в становой тяге показал 210 кг.

Аскольд Суровецкий стал абсолютным победителем конкурса при сложении всех достигнутых результатов.

Естественное желание любого спортсмена - помериться силами с другим, испытать себя в честном соперничестве. Когда появились последователи, стало возможным проводить первенства г. Якутска. В 1988 году состоялся первый чемпионат Якутии по атлетической гимнастике.

Аскольд Суровецкий к этому времени избирается председателем республиканской федерации. Через два года очередное первенство принимает г. Алдан. В том же 1990 г. жители Якутска стали свидетелями первого республиканского конкурса по бодибилдингу. Все высшие награды достались «спартанцам». У юношей победителями стали Вячеслав Волков,
Виталий Горчаков, Сергей Климов, у взрослых - Константин Михайлов, Сергей Развозжаев и Валерий Рябцев.

В 1992 году Суровецкий с учениками в первые выехал за пределы республики. Дебют на турнире по бодибилдингу «Тихоокеанский Аполлон» оказался достаточно успешным - трое вошли в шестерку лучших. На следующий год Вячеслав Волков и Валерий Суханов вернулись из Владивостока с бронзовыми медалями. В 1992 году в Якутске был проведено крупное состязание культуристов, на которое прибыли представители Новосибирска и Нерюнгри. Обладателями приза «Мамонт Якутии-92» стали В. Волков среди юношей и новосибирец Андрей Лопатко среди взрослых. А г. Мирный принял участников первенства республики по пауэрлифтингу. На помост вместе с хозяевами поднялись атлеты городов Алдана и Якутска. Самый большой успех выпал на долю воспитанника «Спарты» Ярослава Чоповского, выступившего в наилегчайшем весе (до 52 кг). В становой тяге Ярослав Чоповский поднял 170 кг, что в 3,4 раза больше его собственного веса. Это достижение стало своего рода трамплином для дальнейших достижений Чоповского. Через год он становится обладателем Кубка России, в 1994 году занимает второе место на чемпионате Российской Федерации. Набрав в сумме троеборья 460 кг, Я. Чоповский первым из клуба «Спарта» становится мастером спорта России. Рядом с ним успешно дебютирует 18-летняя Марина Борисова. Выступая в категории до 60 кг, студентка Якутского государственного университета набрала в сумме троеборья 327,5 кг. Опередив многих конкуренток, она заняла VII место и выполнила норматив мастера спорта.

В настоящее время клуб «Спарта» продолжает традиции, заложенные родоначальниками культуризма, совершенствуется, спортсмены достигают все более высоких показателей. Федерацию бодибилдинга РС (Я) возглавляет «спартанец» Александр Гренадеров - мастер спорта России по бодибилдингу, многократный чемпион и призер Юга России «Самсон», чемпионатов городов 
Москва, Санкт-Петербург, Ростов-на-Дону, Краснодар, Воронеж, Киров, Вологда; чемпион мира, Европы, России по бодибилдингу.

\section{Республиканская}

общественная

организация «Федерация бодибилдинга Республики Саха (Якутия)» была организована в 2016 году. Организация объединяет граждан в целях популяризации спорта и здорового образа жизни и строит свою деятельность по всемерному развитию бодибилдинга по версии IFBB (Международная федерация бодибилдинга) в Республике Саха (Якутия)

Занятия бодибилдингом требуют наличия профессиональных тренеров, острая нехватка которых наблюдается в том числе и в г. Якутске.

Федерация бодибилдинга Якутии образовалась сравнительно недавно, однако уже успела провести 5 чемпионатов Республики Саха (Якутия) по бодибилдингу - ГРАН-ПРИ CAXA.

Руководство Федерации бодибилдинга России высоко оценило качество проводимых мероприятий, поэтому в 2020 году г. Якутск стал площадкой для проведения Чемпионата Дальневосточного федерального округа по бодибилдингу.

За три года федерация бодибилдинга Якутии достигла следующих результатов: были присвоены судейские категории (судья 1-й категории - 1 человек; судья 2-й категории - 10 человек); звание КМС по бодибилдингу было присвоено 1 спортсмену; в 2018, 2019 гг. двое судей были включены в основной состав судейской бригады на Кубках России по бодибилдингу, чемпионатах России по бодибилдингу. Спортсмены из Якутии участвовали в следующих соревнованиях: PACIFIC STRONG - 2018, где Сергей Безьянов стал абсолютным чемпионом по бодибилдингу, Даниил Чернов - чемпионом в дисциплине «Пляжный бодибилдинг». Спортсменки выступают на чемпионатах и Кубках России по бодибилдингув дисциплинах «Фитнес-бикини», «Фит-Модель».

Традиционный Чемпионат Республики Саха (Якутия) по бодибилдингу в 2019 году проходил под девизом 50-летия СК «Спарта». Чемпионат включал следующие дисциплины: бодибилдинг, фитнес-бикини, бодифитнес, фит-модель, пляжный бодибилдинг.

Учитывая положительную

тенденцию и растущий интерес населения к занятиям физической культурой и спортом, положительную динамику роста спортивных залов, можно констатировать, что популяризация вида спорта «бодибилдинг» наращивается. Все больше любителей спорта переходят к профессиональным занятиям бодибилдингом $[7,8,9,10]$.

Роль общественных организаций в области спорта, безусловно, важна, однако требуется и государственная поддержка. В организации деятельности РОО Федерации бодибилдинга РС (Я) можно отметить несколько проблемных моментов, которые требуют решения.

Bo-первых, это отсутствие финансирования со стороны государственных структур. Недостаточное финансирование спортивных федераций - это общая черта всех субъектов Российской Федерации, которая требует кардинального решения. Сегодня растет конкуренция в области спорта. Если регион заинтересован в высоких спортивных достижениях, то необходимо разрабатывать целевые программы с утверждением целевых индикаторов их эффективности. С другой стороны, необходимо проводить конкурсы среди спортивных направлений на получение государственной поддержки.

Во-вторых, это отсутствие материально-технической базы. Главным образом, это проблема улусов РС (Я), где нет даже самого элементарного инвентаря, a желание заниматься бодибилдингом у населения достаточно высокое. Эту проблему можно решить посредством внедрения частногосударственного партнерства. Необходимо заинтересовать частные спортивные компании, прийти к общему взаимовыгодному сотрудничеству.

B-третьих, нехватка профессиональных тренеров в области бодибилдинга. Необходимо 
повышать уровень мастерства, проводить семинары, курсы повышения квалификации, мастер-классы. Все это невозможно проводить только в пределах одного региона. Необходимо получать опыт и знания в тесном контакте с другими регионами, поэтому нужно выезжать на мероприятия как всероссийского, так и международного уровня.

Решение обозначенных проблем позволит вывести бодибилдинг на качественно новый уровень, повысить качество якутских атлетов и заявить о себе на весь мир.

\section{ЗАКЛЮЧЕНИЕ}

Занятия бодибилдингом требуют наличия профессиональных тренеров, острая нехватка которых наблюдается в том числе и в г. Якутске.

Учитывая

положительную тенденцию и растущий интерес населения к занятиям физической культурой и спортом, положительную динамику роста спортивных залов, можно констатировать, что популяризация вида спорта «бодибилдинг» наращивается.

Роль общественных организаций в области спорта, безусловно, важна, однако требуется и государственная поддержка.

В организации деятельности РОО Федерации бодибилдинга РC (Я) имеются проблемы, решение которых позволит вывести бодибилдинг на качественно новый уровень, повысить качество якутских атлетов и заявить о себе на весь мир.

\section{СПИСОК ЛИТЕРАТУРЫ}

1. Степанян C.C., Третьяков М.M.
Молодежный научный форум: общественные и экономические науки. 2017; 5(45): 353-357.

2. Объем платных услуг населению. ЕМИСС. URL: https://fedstat.ru/ indicator $/ 31280 \#$.

3. Роберт Х. Кеннеди. Энциклопедия бодибилдинга: полная книга $A Z$ по наращиванию мыцечной массы. 2008.

4. Соломахина Т.P. Место услуг по физической культуре и спорту в структуре платных услуг населению России. Региональный вестник. 2018; 4(13): 29-32.

5. Фредерик Делавье. Анатомия силовых упражнений. URL: https://zhimlezha.ru.

6. Юрковский А.В. Основные подходы к определению ценностей в правовой аксиологии. Синтез науки и общества в решении глобальных проблем современности. Сборник статей Международной научно-практической конференции. Уфа. 2016: 171-175.

7. Downward P., Rasciute S. Does sport make you happy? An analysis of the well-being derived from sports participation. International Review of Applied Economics. 2011; 25: 331-348. DOI: 10.1080/02692171.2010.511168.

8. Eberth B., Smith M.D. Modelling the participation decision and duration of sporting activity in Scotland. Economic Modelling. 2010; 27: 822-834. DOI: 10.1016/j.econmod.2009.10.003.

9. Federico B., Falese L., Marandola D., Capelli G. Socioeconomic differences in sport physical activity among Italian adults. Journal of Sports Sciences. 2013; 13: 451-458. DOI: 10.1080/02640414.2012.736630.

10. Fridberg T. Sport and exercise in Denmark, Scandinavia and Europe. Sport in Society. 2010; 13: 583-592. DOI: 10.1080/17430431003616225.

Анализ развития рынка фитнес услуг в России.

\section{Статья посупияа в редакцию: 10.10.2020}

Гренадеров Александр Александрович - президент Федерации бодибилдинга Республики Саха (Якутия), 677оо5, Республика Саха (Якутия), г. Якутск, ул. Лермонтова, дом 42 кв. 52 Пономарева Мария Семеновна - кандидат педагогических наук, доцент, Северо-Восточный федеральный университет имени М.К. Аммосова, 677ооо, Республика Саха (Якутия), г. Якутск, ул. Белинского, дом 58, e-mail: ponmarsem@mail.ru

Колодезникова Маргарита Герасимовна - кандидат педагогических наук, профессор, Северо-Восточный федеральный университет имени М.К. Аммосова, 677ооо, Республика Саха (Якутия), г.Якутск, ул. Белинского, дом 58, e-mail:mgkolod@inbox.ru 